\title{
Hyperbaric oxygen protects against myocardial ischemia-reperfusion injury through inhibiting mitochondria dysfunction and autophagy
}

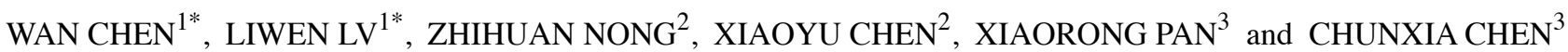 \\ Departments of ${ }^{1}$ Emergency, ${ }^{2}$ Pharmacy and ${ }^{3}$ Hyperbaric Oxygen, The People's Hospital of \\ Guangxi Zhuang Autonomous Region, Nanning, Guangxi 530021, P.R. China
}

Received May 22, 2019; Accepted June 22, 2020

DOI: $10.3892 / \mathrm{mmr} .2020 .11497$

\begin{abstract}
Our previous study demonstrated that hyperbaric oxygen (HBO) improves heart function predominantly through reducing oxygen stress, modulating energy metabolism and inhibiting cell apoptosis. The present study aimed to investigate the protective effects of $\mathrm{HBO}$ on mitochondrial function and autophagy using rats with a ligated left anterior descending artery. The cardioprotective effects of HBO were mainly evaluated using ELISA, fluorescent probes, transmission electron microscopy and reverse transcription-quantitative PCR (RT-qPCR). HBO pretreatment for 14 days (once a day) using a $0.25 \mathrm{MPa}$ chamber improved mitochondrial morphology and decreased the number of autophagic vesicles, as observed using a transmission electron microscope. HBO pretreatment significantly increased the levels of ATP, ADP, energy charge and the opening of the mitochondrial permeability transition pore, but decreased the levels of AMP, cytochrome $c$ and reactive oxygen species. Moreover, HBO pretreatment significantly increased the gene or protein expression levels of eIF4E-binding protein 1, mammalian target of rapamycin (mTOR), mitochondrial DNA, NADH dehydrogenase subunit 1 , mitofusin 1 and mitofusin 2 , whereas it decreased the gene or protein expression levels of autophagy-related 5 (Atg5), cytochrome $c$, dynamin-related protein 1 and $\mathrm{p} 53$, as determined using RT-qPCR or immunohistochemistry. In conclusion, HBO treatment was observed to protect cardiomyocytes during myocardial ischemia-reperfusion injury (MIRI) by preventing mitochondrial dysfunction and inhibiting autophagy. Thus, these results provide novel evidence to support the use of $\mathrm{HBO}$ as a potential agent for the mitigation of MIRI.
\end{abstract}

Correspondence to: Dr Chunxia Chen, Department of Hyperbaric Oxygen, The People's Hospital of Guangxi Zhuang Autonomous Region, 6 Taoyuan Road, Nanning, Guangxi 530021, P.R. China E-mail: chunxia251401@126.com

*Contributed equally

Key words: hyperbaric oxygen, myocardial ischemia-reperfusion injury, mitochondria function, autophagy

\section{Introduction}

Coronary artery ischemic disease is prevalent worldwide (1), it affects $>15$ million adults in the United States (2). A lack of coronary blood supply caused by thrombosis or the acute alteration of coronary atherosclerotic plaques contributes to myocardial ischemia (MI) (3). The early restoration of blood flow is a common treatment strategy (4); however, it can also cause further severe cardiac damage, which is referred to as myocardial ischemia-reperfusion injury (MIRI) $(5,6)$. Therefore, it is of great importance to further investigate safe and effective novel therapeutic treatments to prevent MIRI and improve the clinical outcomes of acute MI.

It is well established that mitochondria are the powerhouses of the cell due to their crucial role in generating ATP (7), but they are also important regulators of programmed cell death pathways (8). Properties of mitochondrial dysfunction include a reduction in energy charge (EC), the opening of the mitochondrial permeability transition pore (mPTP), the release of cytochrome $c$ and $\mathrm{Ca}^{2+}$ overload (9). These properties subsequently lead to mitochondrial membrane depolarization, the homeostatic imbalance between apoptotic proteins, and ultimately cardiomyocyte death (10). Reactive oxygen species (ROS), of which mitochondria are the predominant source, induce MIRI through mitochondrial DNA (mtDNA) damage, reducing energy production and inhibiting protein synthesis through a vicious circle of mitochondrial damage $(11,12)$. In addition, mitochondria are dynamic organelles that continually alter their morphology by undergoing routine fission and fusion events $(13,14)$, which requires specifically controlled proteins; for example, dynamin-related protein 1 (Drp 1), which is a cytosolic GTPase that serves a fundamental role in mitochondrial fission by translocating to the outer mitochondrial membrane to generate the force necessary for mitochondrial fission (15,16), and mitofusin 1 (Mfn1) and mitofusin 2 (Mfn2), which are required for the membrane remodeling processes necessary for mitochondrial fusion $(17,18)$.

Autophagy is an evolutionarily conserved, lysosome-dependent degradation process that is activated during MIRI (19). It has been reported that autophagy serves a dual role in MIRI:A slight induction of autophagy promotes cell survival during ischemia, whilst a significant increase induces 
cell death during reperfusion $(20,21)$. Although a small amount of autophagy can maintain cell function, excessive autophagy was found to promote myocardial injury due to the consumption of cellular constituents (22). Mammalian target of rapamycin (mTOR) kinase is an important regulator of the classical autophagy pathway $(23,24)$, and autophagy related 5 (Atg5) and microtubule-associated protein 1A/1B-light chain 3 (LC3) conjugation systems are required for the formation of autophagic vesicles (25). Eukaryotic initiation factor 4E-binding protein 1 (4E-BP1) binds to eukaryotic initiation factor 4E (eIF4E) (26). The phosphorylation of 4E-BP1 disrupts the assembly of the eIF4E/4E-BP1 complex, which initiates eIF4E-dependent translation, and thereby the activation of cap-dependent mRNA translation (27). In addition to regulating cell cycle checkpoints and apoptosis (28), p53 has also been demonstrated to mediate the transactivation of autophagy inducers $(29,30)$.

Hyperbaric oxygen (HBO) therapy is the clinical application of pure oxygen at a higher pressure (usually 2-3 times atmospheric pressure) in a chamber to treat ischemia- or hypoxia-associated diseases, such as coronary heart disease, cerebral infarction and carbon monoxide poisoning (31-34). HBO therapy has been widely agreed by major hyperbaric craft groups, such as the Undersea and Hyperbaric Medical Society or the U.S. Food and Drug Administration (35). In addition, data from our previous studies demonstrated that $\mathrm{HBO}$ exerted neuroprotective effects in certain animal models; for example, $\mathrm{HBO}$ combined with Madopar protected against 6-hydroxydopamine-induced Parkinson's disease in rats (36) and HBO treatment also alleviated the withdrawal symptoms induced by morphine dependence (37). Moreover, HBO prevented the cognitive impairments induced by $\mathrm{D}$-galactose $(38,39)$. The protective effects of $\mathrm{HBO}$ are mainly associated with the increased induction of antioxidant enzymes and ischemic tolerance, as well as the inhibition of cell apoptosis and the modulation of neurotransmitters (36-39). Previously, our group discovered that HBO preconditioning protected against MI and improved cardiac function (40), of which the underlying mechanisms were associated with the reduction of oxygen stress, the correction of energy metabolism and the inhibition of apoptosis. However, the effect of HBO treatment on mitochondria, and the interaction between mitochondrial dysfunction and autophagy, remain unclear. The present study aimed to investigate the effects of HBO treatment in a rat model of MIRI, established by the ligation of the left anterior descending (LAD) artery, through analyzing mitochondrial function and the mTOR-mediated autophagy pathway.

\section{Materials and methods}

Animal studies. All animal experimental procedures were approved by the Animal Ethical Committee of Guangxi Medical University. A total of 60 healthy Sprague-Dawley rats of both sexes (ratio, 1:1; weight, 180-220 g; age, 6 weeks) were obtained from the Experimental Animal Centre of Guangxi Medical University (Guangxi, China). Animals were housed under controlled conditions at a temperature of $25 \pm 2{ }^{\circ} \mathrm{C}$ and a relative humidity of $60 \pm 10 \%$, with a 12 -h light/dark cycle. Food and water were available ad libitum.
Experimental design and groupings. According to previous guidelines (41), following 1 week of acclimatization to the laboratory conditions, the 60 rats were divided into the following three groups (20 rats/group) using the random number table method: i) Sham group; ii) ischemia-reperfusion (IR) group (MIRI model); and iii) HBO group.

MIRI was inflicted by the occlusion of the LAD coronary artery followed by reperfusion, according to a previous study (40). Briefly, rats were anaesthetized with $30 \mathrm{mg} / \mathrm{kg}$ sodium pentobarbital (i.p.) and mechanically ventilated using an animal respirator (respiration rate, 70 breaths/min; tidal volume, 6-8 ml/kg; Shanghai Alcott Biotech Co., Ltd.). The chest was then opened and the heart was exposed. The LAD artery was ligated using a 5-0 silk suture for $30 \mathrm{~min}$ and released to allow reperfusion for $1 \mathrm{~h}$.

Rats in the IR and HBO groups were subjected to a $30 \mathrm{~min}$ LAD ligation followed by reperfusion for $1 \mathrm{~h}$, whilst the sham group received encircling of the LAD artery with a suture, but no ligation. Before the surgical procedure, rats in the $\mathrm{HBO}$ group were pretreated with $\mathrm{HBO}$ for $1 \mathrm{~h}(0.25 \mathrm{MPa})$ for 14 days (once daily) in a hyperbaric chamber (Yantai Hongyuan Co., Ltd.), as previously described (38).

At the end of the reperfusion, all rats were immediately anesthetized using $30 \mathrm{mg} / \mathrm{kg}$ sodium pentobarbital (i.p.) and were subsequently euthanized through exsanguination by collecting $8 \mathrm{ml}$ blood from the abdominal aorta. Death was confirmed following the detection of a still heartbeat, and when breathing had stopped. Blood samples were centrifuged at $302 \mathrm{x} \mathrm{g}$ for $10 \mathrm{~min}$ at $4^{\circ} \mathrm{C}$, and the supernatant was collected and stored at $-80^{\circ} \mathrm{C}$ for use in the biochemical assays. The heart was promptly removed from the rats and the infarct was isolated on an ice box for further measurements.

Determination of ATP, ADP, AMP and cytochrome c levels in $M I$ tissue. Myocardial samples $(\mathrm{n}=5)$ were homogenized in ice-cold physiological saline $(10 \%, \mathrm{w} / \mathrm{v})$ and centrifuged at $3,354 \mathrm{x} \mathrm{g}$ for $10 \mathrm{~min}$ at $4^{\circ} \mathrm{C}$ to collect the supernatant. ATP and ADP levels were determined using ATP and ADP assay kits, respectively (colorimetric method; cat. nos. ab83355 and ab83359; Abcam), according to the manufacturer's protocols. AMP and cytochrome $c$ levels were determined using an AMP ELISA kit (cat. no. tw045885; Shanghai Tongwei Biological Technology, Co., Ltd.) and a cytochrome $c$ ELISA kit (cat. no. ab210575; Abcam), respectively, and a SpectraMax Plus 384 microplate reader (Molecular Devices, LLC). The EC was calculated using the following formula: (ATP+0.5 ADP)/(ATP+ADP+AMP).

Measurement of intracellular ROS levels and opening of the mPTP. Intracellular ROS and mPTP openings were detected using dihydroethidium (DHE; $10 \mu \mathrm{M}$ ) and calcein-AM fluorescent probes as permeabilization reagents, respectively $(\mathrm{n}=5)$. PBS solution $\left(37^{\circ} \mathrm{C}, 1 \mathrm{~min}\right)$ was used as blocking reagent. Briefly, fresh frozen myocardial specimens were cut into $10-\mu \mathrm{m}$ sections using a Leica CM1950 frozen section machine (Leica Microsystems $\mathrm{GmbH}$ ). According to the manufacturer's protocol, sections were incubated with $10 \mu \mathrm{M}$ DHE (cat. no. GMS10111.2; Genmed Scientific, Inc.) and $10 \mu \mathrm{M}$ Calcein-AM (cat. no. GMS12705, Genmed Scientific, Inc.) for $\sim 30 \mathrm{~min}$ at $37^{\circ} \mathrm{C}$ and subsequently washed with 
Table I. Primer sequences for reverse transcription-quantitative PCR.

\begin{tabular}{|c|c|}
\hline Gene & Primer sequence $\left(5^{\prime} \rightarrow 3^{\prime}\right)$ \\
\hline \multirow[t]{2}{*}{ NADH dehydrogenase subunit 1} & F: CGGCTCCTTCTCCCTACAA \\
\hline & R: ATGGTCCTGCGGCGTATT \\
\hline \multirow[t]{2}{*}{ Cytochrome $c$} & F: CCCCTGCTATAACCCAATACA \\
\hline & R: CCAAACCCTGGAAGAATTAAGA \\
\hline \multirow[t]{2}{*}{ GAPDH } & F: TGTTGCTGTAGCCATATTCATTGT \\
\hline & R: CCATTCTTCCACCTTTGATGCT \\
\hline \multirow[t]{2}{*}{ Dynamin-related protein 1} & F: CGTAGTGGGAACTCAGAGCA \\
\hline & R: TGGACCAGCTGCAGAATAAG \\
\hline \multirow[t]{2}{*}{ Mitofusin 1} & F: GCTGCATACAGACAGACAGCCT \\
\hline & R: GGTAATGACCTGTCTCAGGGCT \\
\hline \multirow[t]{2}{*}{ Mitofusin 2} & F: GAACTTGTGTCTTGCATTTGGC \\
\hline & R: TGCAGGCCTAACTCCTCCCAC \\
\hline \multirow[t]{2}{*}{$\beta$-actin } & F: CCTCTATGCCAACACAGTGC \\
\hline & R: ATACTCCTGCTTGCTGATCC \\
\hline \multirow[t]{2}{*}{ mTOR } & F: GTGTGGCAAGAGCGGCAGAC \\
\hline & R:TGTTGGCAGAGGATGGTCAAGTTG \\
\hline \multirow[t]{2}{*}{ p53 } & F: GTCACCTCCACACCTCCACCTG \\
\hline & R: TGCCTGTCGTCCAGATACTCAGC \\
\hline \multirow[t]{2}{*}{ GAPDH } & F: GGAGAAGGAGCAGGAGAATC \\
\hline & R: GAGACAGACAGGAGGTGATG \\
\hline
\end{tabular}

F, forward; R, reverse.

$0.1 \mathrm{~mol} / 1 \mathrm{PBS}$ solution. Stained sections were visualized using a fluorescence microscope at a magnification of x200 (Olympus Corporation). The average fluorescence intensity was calculated using Image-ProPlus version 6.0 software (Media Cybernetics, Inc.).

Transmission electron microscopy. Myocardial infarct tissue $\left(\sim 1 \mathrm{~mm}^{3} ; \mathrm{n}=5\right)$ was fixed in $2.5 \%$ glutaraldehyde overnight at $4^{\circ} \mathrm{C}$, rinsed with PBS (pH 7.2) and subsequently fixed in $1 \%$ osmium tetroxide for $3 \mathrm{~h}$ at $4^{\circ} \mathrm{C}$. Samples were dehydrated in an increasing concentration ethanol series, then embedded in epoxy resin overnight at $60^{\circ} \mathrm{C}$. Embedded sections were cut into 70-nm thick slices and stained with $3 \%$ uranium acetate and lead citrate for $15 \mathrm{~min}$ at $37^{\circ} \mathrm{C}$. The ultrastructures of myocardial cells, including the mitochondria, intercalated discs, myofilaments and autophagosomes, were observed using a Hitachi H-7650 transmission electron microscope at magnifications of $\mathrm{x} 15,000$ and $\mathrm{x30,000}$ (Hitachi High-Technologies Corporation) and analyzed using RADIUS 2.0 (EMSIS GmbH).

Immunohistochemistry of 4E-BP1, Atg5and mTOR expression levels. At the end of reperfusion, myocardial tissue $(\mathrm{n}=5)$ was fixed in $4 \%$ buffered paraformaldehyde solution overnight at $4^{\circ} \mathrm{C}$. After processing with routine histological procedures (dehydration, transparent, dipped wax and embedding), paraffin-embedded tissues were cut into $4 \mu \mathrm{m}$-thick sections. The tissue sections were subsequently deparaffinized with xylene at $37^{\circ} \mathrm{C}$ and rehydrated in a descending series of alcohol. Sections were incubated in $0.01 \mathrm{M}$ sodium citrate buffer solution ( $\mathrm{pH} 6.0$ ) for $\sim 15 \mathrm{~min}$ at $100^{\circ} \mathrm{C}$ for antigen retrieval and then blocked in $10 \%$ goat serum (cat. no. 701323A; Beijing Zhongsan Jinqiao Biotechnology Co., Ltd.) for $15 \mathrm{~min}$ at room temperature. Tissue sections were incubated with primary antibodies against 4E-BP1 (1:100; cat. no. ab131453; Abcam), Atg5 (1:100; cat. no. ab227084; Abcam) and mTOR (1:100; cat. no. ab32028; Abcam) overnight at $4^{\circ} \mathrm{C}$. Following the primary incubation, sections were incubated with a biotinylated goat anti-rabbit immunoglobulin $\mathrm{G}$ secondary antibody (100 $\mu \mathrm{l}$ per section) for $25 \mathrm{~min}$ at $37^{\circ} \mathrm{C}$ and then a streptavidin-biotin complex (100 $\mu \mathrm{l}$ per section) for $15 \mathrm{~min}$ at $37^{\circ} \mathrm{C}$ (both from the same kit; cat. no. SAP-9100; Beijing Zhongsan Jinqiao Biotechnology Co., Ltd.) for $20 \mathrm{~min}$ at room temperature. The slides were subsequently stained with 3,3'-diaminobenzidine for $15 \mathrm{~min}$ and 4E-BP1-, Atg5- and mTOR-positive cells were observed under a light microscope (magnification, x200; Olympus Corporation). In total, five fields of each section were captured using a Leica DM6000 digital camera (Leica Microsystems $\mathrm{GmbH}$ ).

Measurement of mtDNA copy number. DNA was extracted from ischemic myocardial tissue using a mitochondrial DNA isolation kit (Abnova) (7). PCR amplification (TaKaRa Ex Taq HSasDNA polymerase; Takara Bio, Inc.) and analysis were performed using a 7500 Real-Time PCR system equipped with SDS software v2.0 (Applied Biosystems; Thermo Fisher Scientific, Inc.). The thermal cycling conditions were: Initial denaturation at $95^{\circ} \mathrm{C}$ for $30 \mathrm{sec}$, followed by 40 cycles of $95^{\circ} \mathrm{C}$ for $5 \mathrm{sec}, 55^{\circ} \mathrm{C}$ for $30 \mathrm{sec}$ and $72^{\circ} \mathrm{C}$ for $30 \mathrm{sec}$. The following primer pairs were used for the PCR: mtDNA (238 bp) forward, 

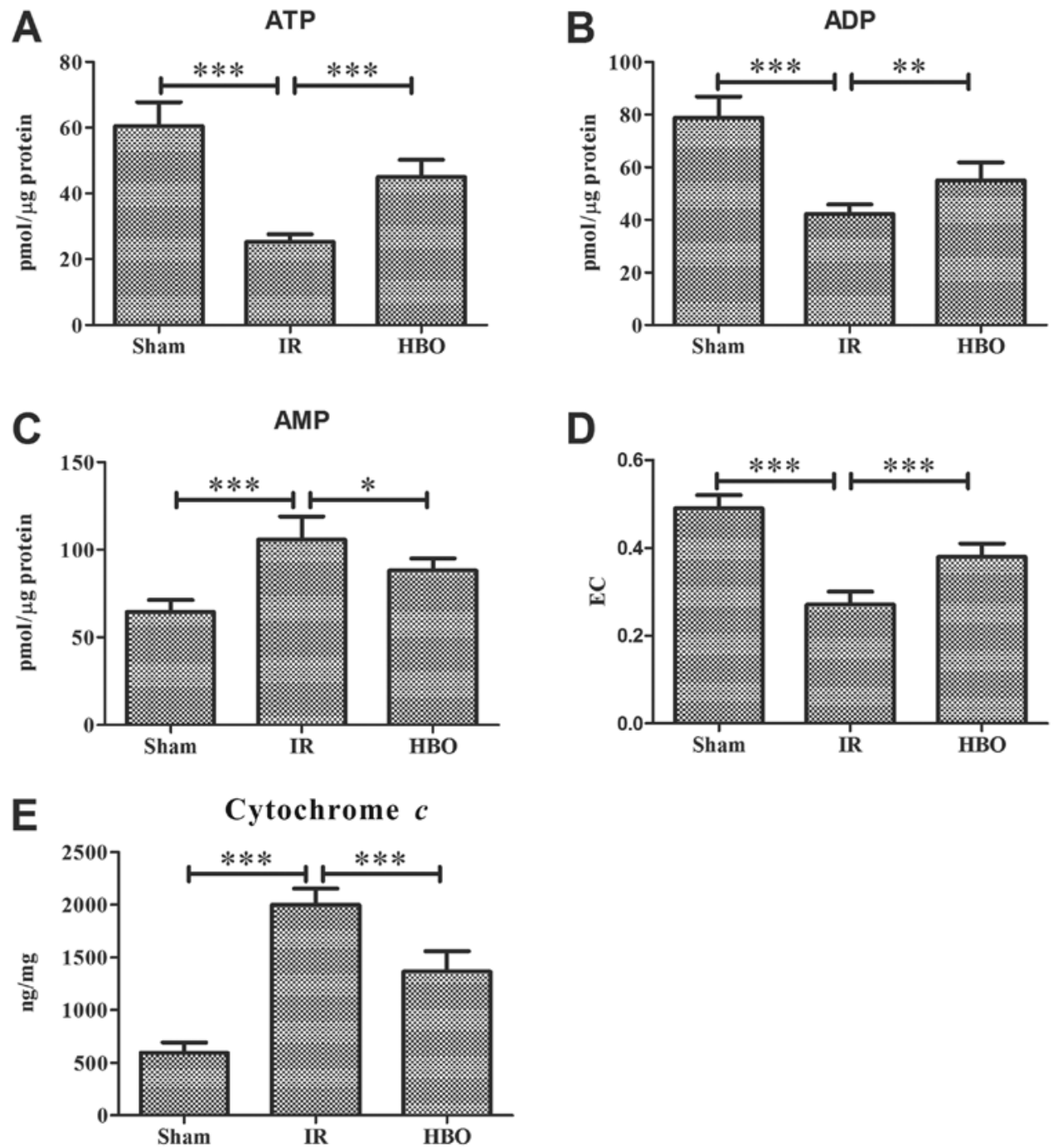

Figure 1. Effect of HBO pretreatment on ATP, ADP, AMP and cytochrome $c$ expression levels and EC in myocardial infarction tissue. Expression levels of (A) ATP and (B) ADP were determined using specific assay kits in the sham, IR and HBO groups. (C) AMP expression levels were detected using an ELISA kit in the sham, IR and HBO groups. (D) EC was determined in the sham, IR and HBO groups. (E) Cytochrome $c$ expression levels were determined using an ELISA in the sham, IR and HBO groups. Data are presented as the mean $\pm \mathrm{SD}(\mathrm{n}=5) .{ }^{*} \mathrm{P}<0.05 ;{ }^{* * *} \mathrm{P}<0.01 ;{ }^{* * * *} \mathrm{P}<0.001$. HBO, hyperbaric oxygen; EC, energy charge; IR, ischemia/reperfusion.

5'-CCCCTGCTATAACCCAATACA-3' and reverse, 5'-CCA AACCCTGGAAGAATTAAGA-3'; GAPDH (98 bp) forward, 5'-TGCTGTAGCCATATTCATTGT-3' and reverse, 5'-CCA TTCTTCCACCTTTGATGCT-3'. mtDNA copy number was normalized to GAPDH $(\mathrm{n}=5)$.

Reverse transcription-quantitative $P C R$ (RT-qPCR). RT-qPCR was performed according to previously described method (38). Briefly, total RNA was extracted from the ischemic myocardial tissue using TRIzol ${ }^{\circledR}$ reagent (Invitrogen; Thermo Fisher Scientific, Inc.), according to the manufacturer's instructions. RNA was quantified using a spectrophotometer (Thermo Fisher Scientific, Inc.) at an optical density of $260 / 280 \mathrm{~nm}$. A total of $1 \mu \mathrm{g}$ RNA was reverse-transcribed into cDNA using the PrimeScriptTM RT Reagent kit with gDNA Eraser (Takara Bio, Inc.), according to the manufacturer's protocol. The following RT temperature protocol was used: $37^{\circ} \mathrm{C}$ for $15 \mathrm{~min}$, followed by $85^{\circ} \mathrm{C}$ for $5 \mathrm{sec}$ and $4^{\circ} \mathrm{C}$ for $5 \mathrm{~min}$. The qPCR reaction was subsequently performed in a reaction mixture containing $2 \mu \mathrm{l}$ cDNA
(500 ng/ $\mu \mathrm{l}), 0.8 \mu \mathrm{l}$ forward primer $(10 \mu \mathrm{M}), 0.8 \mu 1$ reverse primer $(10 \mu \mathrm{M}), 10 \mu 12 \mathrm{X}$ SYBR Premix Ex Taq ${ }^{\mathrm{TM}}$ II (Takara Bio, Inc.), $0.4 \mu \mathrm{l}=50 \mathrm{X}$ ROX Reference Dye or Dye II (Takara Bio, Inc.) and $6 \mu \mathrm{l}$ RNase-Free $\mathrm{dH}_{2} \mathrm{O}$ (final volume: $20 \mu \mathrm{l}$ ) using a 7500 Real Time PCR system (Applied Biosystems; Thermo Fisher Scientific, Inc.). The primer pairs used for the qPCR were synthesized by Sangon Biotech Co., Ltd. and are presented in Table I. The following thermocycling conditions were used for the qPCR: $95^{\circ} \mathrm{C}$ for $30 \mathrm{sec} ; 40$ cycles of $95^{\circ} \mathrm{C}$ for $5 \mathrm{sec}$ and $60^{\circ} \mathrm{C}$ for $30 \mathrm{sec}$. Expression levels were quantified using the $2^{-\Delta \Delta C q}$ method (42) and GAPDH and $\beta$-actin were used as the internal reference controls $(n=5)$.

Statistical analysis. Statistical analysis was performed using the Statistics Package for Social Science in SPSS version 13.0 software (SPSS, Inc.). Data are expressed as the mean \pm SD. Statistical differences between groups was determined using a one-way ANOVA followed by a LSD post hoc test for multiple comparisons. $\mathrm{P}<0.05$ was considered to indicate a statistically significant difference. 


\section{Results}

Effect of $\mathrm{HBO}$ pretreatment on mitochondrial function. The levels of AMP in the MI tissue were significantly increased by $164 \%$ in the IR group compared with the sham group (105.8 \pm 13.16 vs. $64.4 \pm 6.88 ; F=24.280 ; P<0.001$; Fig. $1 C$ ), whereas the ATP and ADP levels were significantly decreased by $58.28 \%$ (25.2 \pm 2.39 vs. $60.4 \pm 7.37 ; \mathrm{F}=53.378$; $\mathrm{P}<0.001$; Fig. 1A) and $46.19 \%(42.4 \pm 3.36$ vs. $78.8 \pm 8.17$; $\mathrm{F}=40.84$; $\mathrm{P}<0.001$; Fig. 1B), respectively. In the HBO group compared with the IR group, the AMP levels were reduced by $16.64 \%(88.2 \pm 6.80 ; \mathrm{P}<0.05)$, and the ATP and ADP levels were increased by $78.57 \%(45.0 \pm 5.24 ; \mathrm{P}<0.001)$ and $29.72 \%$ (55.0 $\pm 6.89 ; \mathrm{P}<0.01)$, respectively. Moreover, the level of EC was significantly decreased following MIRI surgery (IR group) compared with the sham group $(0.27 \pm 0.03$ vs. $0.49 \pm 0.03$; $\mathrm{F}=63.275$; $\mathrm{P}<0.001$; Fig. 1D), whereas the pretreatment with $\mathrm{HBO}$ in the HBO group significantly increased the EC level compared with the IR group $(0.38 \pm 0.03 ; \mathrm{P}<0.001)$.

To determine whether HBO pretreatment influenced the inner mitochondrial membrane, the activity of cytochrome $c$ was analyzed at the end of reperfusion. The levels of cytochrome $c$ in the MI tissue were 2.36-fold higher in the IR group compared with the sham group $(1,994.8 \pm 155.9$ vs. $594.0 \pm 98.9$; $\mathrm{F}=102.836$; $\mathrm{P}<0.001$; Fig. 1E); however, these levels were partly recovered in the HBO group $(1,363.0 \pm 194.11 ; \mathrm{P}<0.001$; Fig. 1E).

Effect of HBO pretreatment on intracellular ROS levels and mPTP opening. The levels of ROS and mPTP opening in myocardial tissue was investigated in response to MIRI using frozen sections and fluorescent probes. The relative fluorescent level of ROS in the IR group was significantly increased compared with the sham group ( $\mathrm{F}=39.325$; $\mathrm{P}<0.001$; Fig. 2A), whereas the levels were significantly decreased following HBO pretreatment $(\mathrm{P}<0.05)$. Compared with the sham group, the relative fluorescence level of calcein-AM in IR rats was significantly reduced $(\mathrm{F}=32.905 ; \mathrm{P}<0.001$; Fig. $2 \mathrm{~B})$, whereas it was significantly increased in the $\mathrm{HBO}$ group $(\mathrm{P}<0.05)$.

Morphological changes of myocardial cells. Autophagic vesicles were rarely observed in the sham group. In order to highlight the contrast of the groups, only Fig. 3A is shown as a representative of the sham group. Rats in the sham group demonstrated a normal myofilament distribution, with clear light and shade, complete intercalated disks and an intact, normal morphology of mitochondria (Fig. 3A); however, in the IR group, myocardial cells exhibited signs of myofilament disorders, sarcoplasmic reticulum dilatation and mitochondrial damage (Fig. 3A), in addition to significantly increased numbers of autophagic vesicles compared with the sham group (Fig. 3B). Notably, these ultrastructural changes observed in the IR group were improved in the HBO group, which exhibited only a small number of autophagic vacuoles and slight damage to the mitochondria (Fig. 3) compared with the IR group.

Effect of $H B O$ pretreatment on 4E-BPl, Atg5 and mTOR expression levels in myocardial tissue. As indicated by the staining with brown granules, 4E-BP1 and Atg5 protein
A

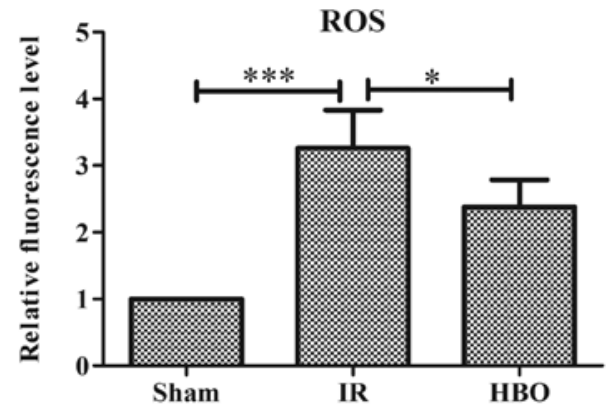

B

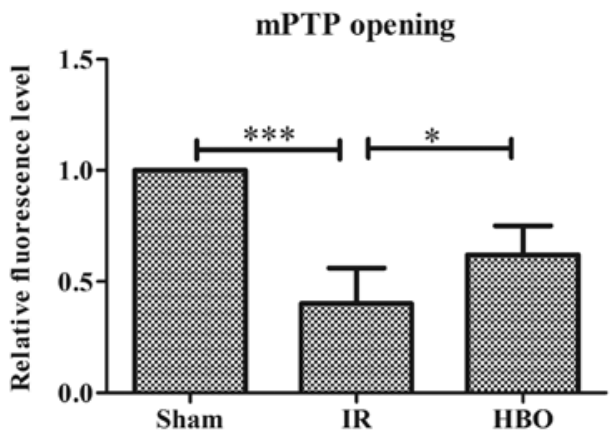

Figure 2. Effect of HBO pretreatment on the levels of intracellular ROS and mPTP opening in myocardial tissue. Tissues were incubated with (A) DHE and (B) mPTP opening to determine the intracellular levels of ROS and mPTP opening, respectively, in the sham, IR and HBO groups. Data are presented as the mean $\pm \mathrm{SD}(\mathrm{n}=5)$. ${ }^{*} \mathrm{P}<0.05 ;{ }^{* * *} \mathrm{P}<0.001$. Data were normalized to the sham group. HBO, hyperbaric oxygen; ROS, reactive oxygen species; $\mathrm{mPTP}$, mitochondrial permeability transition pore; IR, ischemia/reperfusion; DHE, dihydroethidium.

expression was mainly observed to be located in the cytoplasm, whereas mTOR protein was located in the nucleus (Fig. 4A). The staining intensity of 4E-BP1 was significantly decreased in the IR group compared with the sham group $\left(\mathrm{F}_{4 \mathrm{E}-\mathrm{BP} 1}=44.685 ; \mathrm{P}<0.001\right.$; Fig. $4 \mathrm{~A}$ and $\left.\mathrm{B}\right)$, whereas the Atg5 staining intensity was significantly increased $\left(\mathrm{F}_{\mathrm{Atg} 5}=338.150\right.$; $\mathrm{P}<0.001$; Fig. 4A and $\mathrm{C}$ ). Notably, $\mathrm{HBO}$ pretreatment significantly alleviated these alterations observed in the IR group $(\mathrm{P}<0.01$ or $\mathrm{P}<0.001$; Fig. $4 \mathrm{~A}-\mathrm{C})$. In addition, the number of mTOR-positive cells was significantly decreased in the IR group compared with the sham group $(\mathrm{F}=106.408 ; \mathrm{P}<0.001$; Fig. 4A and D), whilst the number of mTOR-positive cells were significantly increased in the HBO group compared with the IR group $(\mathrm{P}<0.001)$.

Effect of $\mathrm{HBO}$ pretreatment on mtDNA damage. A significantly decreased mtDNA copy number was observed in the myocardial tissue of the IR group compared with the sham group $(\mathrm{F}=260.906 ; \mathrm{P}<0.001 ;$ Fig. 5). In contrast, the HBO group had significantly increased mtDNA copy numbers compared with the IR group $(\mathrm{P}<0.001)$.

Effect of HBO pretreatment on the mRNA expression levels of mitochondrial dynamic-and autophagy-related genes. The mRNA expression levels of NADH dehydrogenase subunit 1 (ND1), Mfn1 and Mnf2 were significantly decreased by $\sim 68.42,71.69$ and $66.58 \%$, respectively, in the IR group compared with the sham group (ND1, $0.24 \pm 0.05$ vs. $0.76 \pm 0.09$; $\mathrm{F}=46.316 ; \mathrm{P}<0.001 ; \mathrm{Mfn} 1,0.24 \pm 0.06$ vs. $0.85 \pm 0.05 ; \mathrm{F}=75.189$; 
A

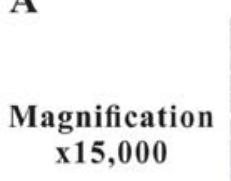

Magnification $\mathbf{x} 30,000$
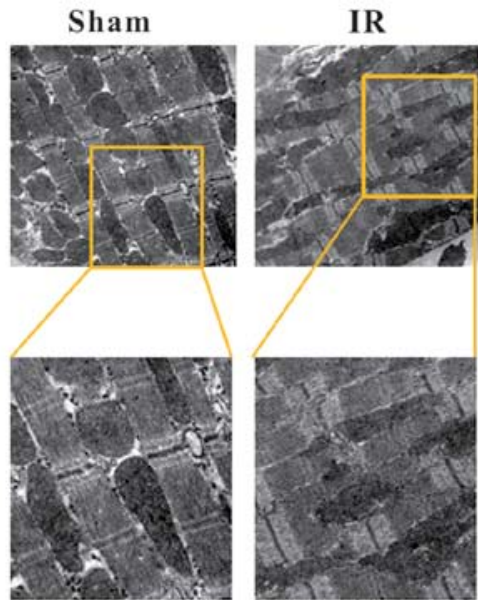

HBO
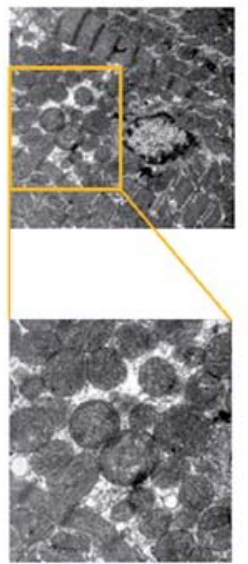

IR

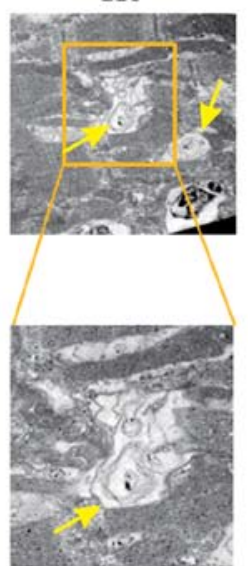

HBO

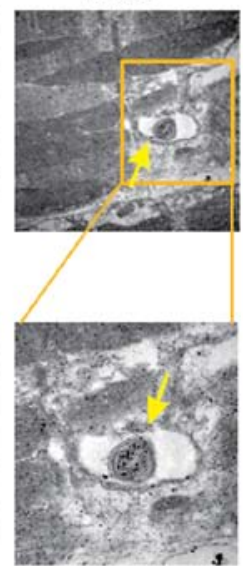

B

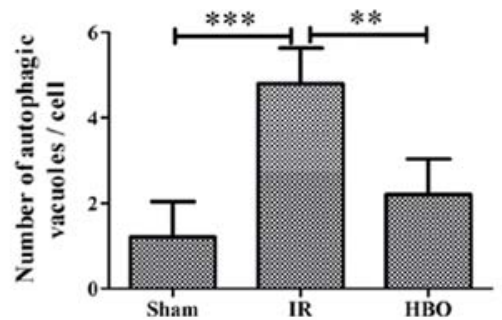

Figure 3. Effect of HBO pretreatment on myocardial ultrastructure. (A) Representative micrograph of the myocardial tissue in the sham, IR and HBO group. Normal mitochondria and no autophagic vacuoles were observed in the sham group. Significant damage to the mitochondria and increased numbers of autophagic vacuoles were observed in the IR group, compared with the sham group. Only slight damage to the mitochondria and decreased numbers of autophagic vacuoles were observed (concentric circle changes) in the HBO group, compared with the IR group. Magnification, x15,000 and x30,000. The yellow arrow indicates autophagic vacuoles. (B) Semi-quantification of the number of autophagic vacuoles from sham group, IR group and HBO group (n=5). ${ }^{* *} \mathrm{P}<0.01 ;{ }^{* * *} \mathrm{P}<0.001$. IR, ischemia/reperfusion; HBO, hyperbaric oxygen.

A
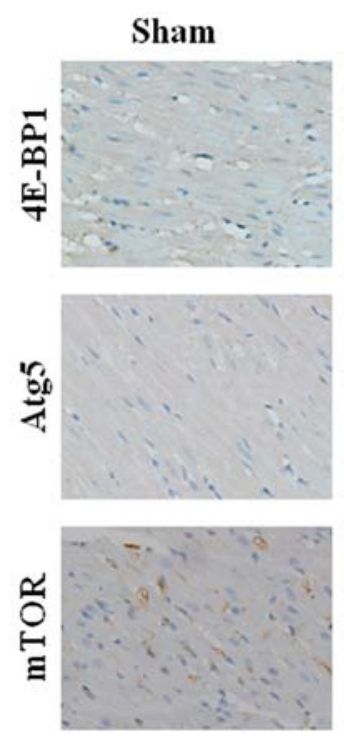

IR
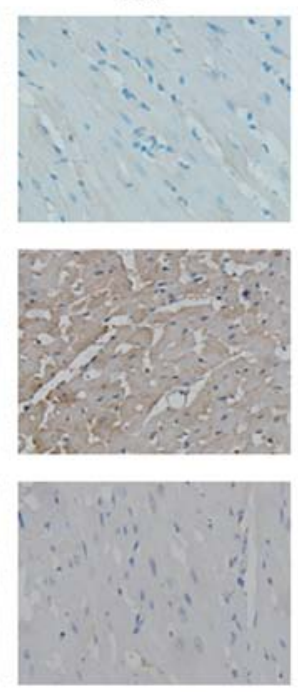

HBO
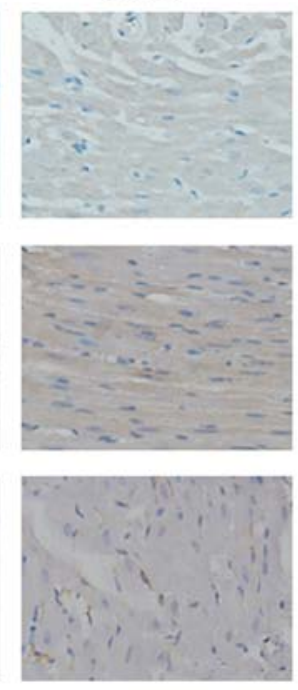

B

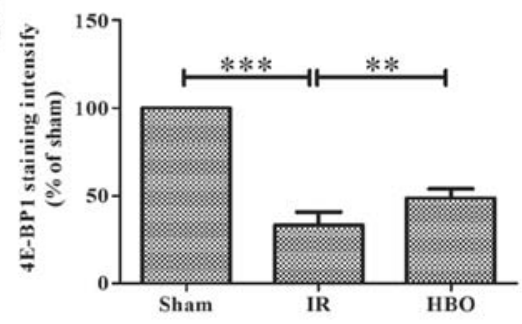

C

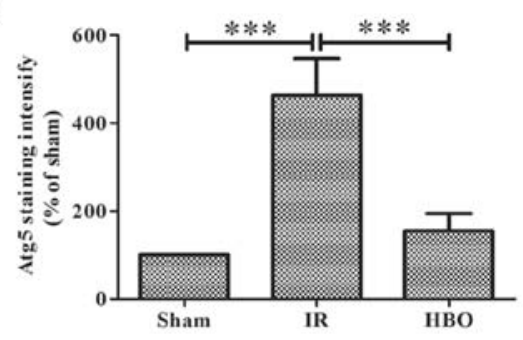

D

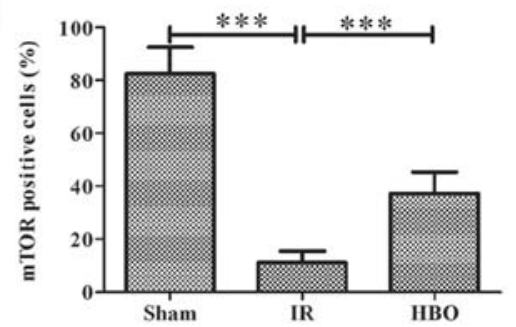

Figure 4. Effect of $\mathrm{HBO}$ pretreatment on 4E-BP1, Atg5 and mTOR expression levels in myocardial tissue. (A) Immunohistochemical staining of myocardial sections to detect the expression levels of 4E-BP1, Atg5 and mTOR in the sham, IR and HBO groups. Nuclei were stained blue and the target proteins were stained brown. Magnification, x400. Semi-quantification of (B) 4E-BP1, (C) Atg5 and (D) mTOR expression levels in the sham, IR and HBO groups. Data are normalized to the sham group and presented as percentages. Data are presented as the mean $\pm \mathrm{SD}(\mathrm{n}=5) .{ }^{* *} \mathrm{P}<0.01 ;{ }^{* * * *} \mathrm{P}<0.001$. IR, ischemia/reperfusion; HBO, hyperbaric oxygen; Atg5, autophagy-related 5; 4E-BP1, eukaryotic initiation factor 4E-binding protein 1; mTOR, mammalian target of rapamycin. 


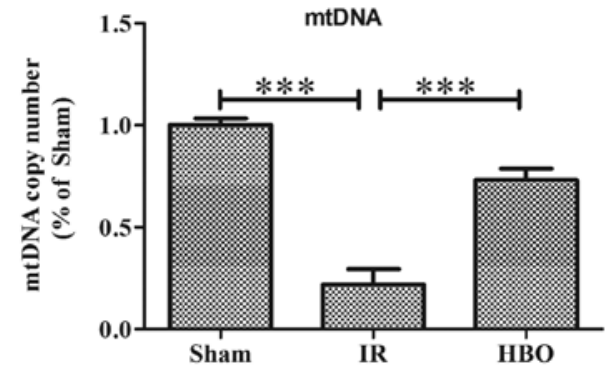

Figure 5. Effect of HBO pretreatment on mtDNA copy number. Data were normalized to the sham group and presented as percentages. Data are presented as the mean $\pm \mathrm{SD}(\mathrm{n}=5) .{ }^{* * *} \mathrm{P}<0.001$. mtDNA, mitochondrial DNA

$\mathrm{P}<0.001 ; \mathrm{Mfn} 2,0.25 \pm 0.06$ vs. $0.74 \pm 0.05 ; \mathrm{F}=61.543 ; \mathrm{P}<0.001 ;$ Fig. 6A, D and E). The mRNA expression levels of cytochrome $c$ and Drp1+ were 117 and $212 \%$ higher, respectively, in the IR group compared with the sham group, respectively (cytochrome $c, 0.72 \pm 0.06$ vs. $0.33 \pm 0.09 ; \mathrm{F}=27.699 ; \mathrm{P}<0.001 ; \mathrm{Drp1}$, $0.76 \pm 0.11$ vs. $0.24 \pm 0.06 ; \mathrm{F}=45.180 ; \mathrm{P}<0.001$; Fig. $6 \mathrm{~B}$ and $\mathrm{C}$ ). Notably, the mRNA expression levels of ND1, Mfn1, cytochrome $c$, Drp1 and Mfn2 were significantly reversed in rats in theHBO group compared with rats in the IR group (ND1, $0.62 \pm 0.11, \mathrm{P}<0.001 ; \mathrm{Mfn} 1,0.54 \pm 0.11, \mathrm{P}<0.001$; cytochrome $c$, $0.58 \pm 0.10, \mathrm{P}<0.05 ; \mathrm{Drp1}, 0.54 \pm 0.08, \mathrm{P}<0.01 ; \mathrm{Mfn} 2,0.50 \pm 0.09$; $\mathrm{P}<0.01)$.

The expression levels of autophagy-related genes were subsequently investigated; significantly decreased expression levels of mTOR mRNA $(0.17 \pm 0.06$ vs. $0.73 \pm 0.07 ; \mathrm{F}=84.943$; $\mathrm{P}<0.001$; Fig. $6 \mathrm{~F}$ ) and significantly increased expression levels of p53 mRNA ( $0.83 \pm 0.06$ vs. $0.22 \pm 0.08 ; \mathrm{F}=80.131 ; \mathrm{P}<0.001$; Fig. 6G) were observed in the IR group compared with the sham group. Notably, rats pretreated with HBO exhibited significantly increased mTOR expression levels $(0.61 \pm 0.09$ $\mathrm{P}<0.001)$ and significantly decreased expression levels of p53 $(0.52 \pm 0.08 ; \mathrm{P}<0.001)$ compared with the IR group.

\section{Discussion}

The present study investigated the effects of HBO pretreatment on rats undergoing MIRI. In our previous study, it was observed that HBO preconditioning attenuated MIRI in rats, mainly through reducing oxygen stress damage, correcting energy metabolism and inhibiting cell apoptosis (40). In the present study, it was identified that HBO pretreatment protected the integrity of the mitochondria and decreased cardiomyocyte autophagy, as observed using a transmission electron microscope. Mechanistically, these findings suggested that HBO may participate in regulating mitochondrial function and inhibiting autophagy through the mTOR signaling pathway. In addition, the results indicated that HBO may exert an important protective function against MIRI, with our study providing experimental data for the clinical application of HBO.

Mitochondrial function serves important roles in the MIRI process (43); excessive oxidative stress results in a collapse in the mitochondrial membrane structure and mitochondrial membrane potential $\left(\Delta_{\psi \mathrm{m}}\right)(44)$. Following a period of ischemia, reperfusion of the oxygen supply is found to produce an excessive amount of ROS, which triggers oxidative stress (45). Our previous study demonstrated that oxidative stress parameters, such as superoxide dismutase, malondialdehyde and glutathione peroxidase, were activated in MIRI model rats (40). Consistent with our previous study, in the present study MIRI promoted higher relative fluorescence levels of ROS in the myocardial tissue. In addition, in IR rats, ATP and ADP levels were decreased, whereas AMP levels were increased, and the EC was also decreased in IR rats. Notably, HBO pretreatment was observed to significantly reverse all of these changes.

Due to energy homeostasis dysfunction, the loss of ATP leads to the disruption of ionic pumps systems, such as $\mathrm{Na}^{+}-\mathrm{K}^{+}$-ATPase and $\mathrm{Ca}^{2+}-\mathrm{Mg}^{2+}$-ATPase. The latter results in increased intracellular and mitochondrial $\mathrm{Ca}^{2+}$, which was found to further accelerate ATP depletion (46). Our previous study found that the function of $\mathrm{Na}^{+}-\mathrm{K}^{+}$-ATPase and $\mathrm{Ca}^{2+}-\mathrm{Mg}^{2+}$-ATPase tended to be disrupted in MIRI rats, as well as the regulation effect of $\mathrm{HBO}$ on the two ATPase (40). Factors, including the decreased levels of ATP, influx of extracellular $\mathrm{Ca}^{2+}$ and oxidative stress $(47,48)$, are suggested to accelerate the opening of the mPTP. Additionally, abnormal activities during mitochondrial fission and fusion may reduce the $\Delta_{\psi \mathrm{m}}$, which has been found to lead to the elimination of these mitochondria through autophagy (49). In the present study, the opening of the MPTP in intact cells was investigated by monitoring the fluorescence of mitochondrial-entrapped calcein. Using the MIRI model rats, a rapid decrease in calcein-AM fluorescence was observed in the IR group, which suggested the increased opening of the mPTP. In contrast, HBO pretreatment inhibited mPTP opening, as evidenced by increased fluorescence intensity. As a subunit of oxidative phosphorylation, cytochrome $c$ detaches from the mitochondrial inner membrane and leaks into the cytoplasm following the opening of the mPTP $(50,51)$. In accordance with these findings, our data demonstrated that the levels of cytochrome $c$ were significantly increased in the IR group compared with the sham group, whereas HBO pretreatment was able to dampen these changes.

In the mitochondrial genome, mtDNA comprises a naked circular strand of DNA of $16.5 \mathrm{~kb}$ (52), which encodes 13 polypeptides involved in oxidative phosphorylation (53). The results from the present study indicated that mtDNA damage occurred, as its corresponding transcription level was decreased during MIRI, which was consistent with the excessive cellular ROS production observed in the cardiomyocytes. Notably, mtDNA copy number and ND1 expression levels were increased following $\mathrm{HBO}$ pretreatment in rats subjected to MIRI. ND1 is encoded by the light chain of mtDNA, thus it reflects the transcription level of mtDNA (54). In addition, previous studies have reported that mitochondrial fission and fusion are important events in MIRI $(55,56)$. In fact, the inactivation of Drp1 and the activation of Mfn2 helped improve the mitochondrial dynamic parameters and delayed the development of MIRI (57). In the present study, the results implied that the balance between mitochondrial fission and fusion was disrupted by the mRNA increasing expression level of Drp1, while decreasing expression levels of Mnf1 and Mnf2 in MIRI. However, Drp1 expression levels were subsequently decreased with HBO pretreatment, while Mnf1 and Mnf2 expression levels were increased following HBO pretreatment. These findings suggested that HBO pretreatment may provide cardiac 

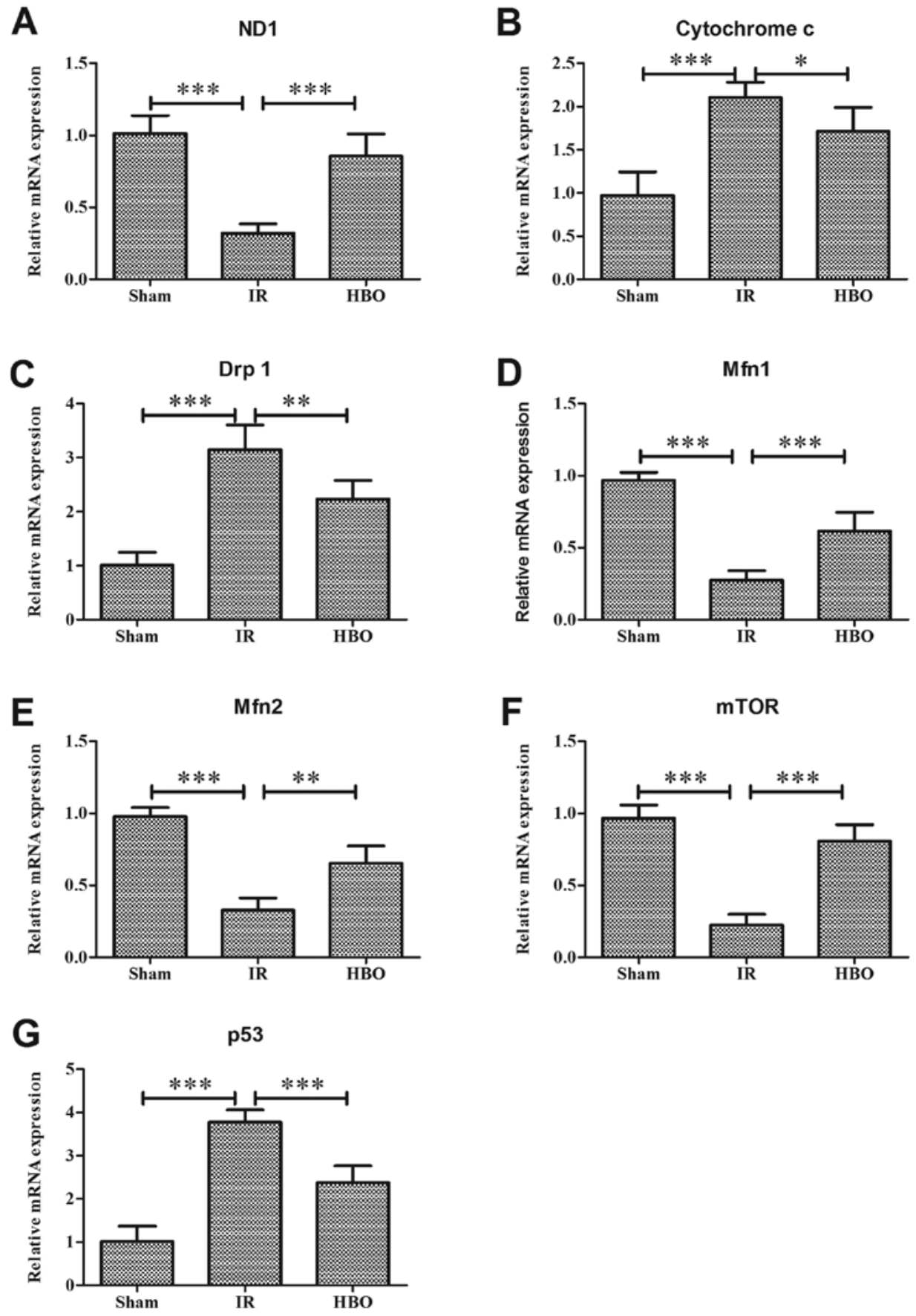

Figure 6. Statistical analysis of reverse transcription-quantitative PCR results. (A-E) Effect of HBO pretreatment on the mRNA expression levels of mitochondrial dynamics-related genes: (A) ND1, (B) cytochrome $c$, (C) Drp1, (D) Mfn1 and (E) Mfn2 in the sham, IR and HBO groups. Effect of HBO pretreatment on the expression levels of autophagy-related genes: (F) mTOR and (G) p53 in the sham, IR and HBO groups. Data are presented as the mean \pm SD (n=5). ${ }^{*} \mathrm{P}<0.05 ;{ }^{* *} \mathrm{P}<0.01 ;{ }^{* * *} \mathrm{P}<0.001$. HBO, hyperbaric oxygen; IR, ischemia/reperfusion; ND1, NADH dehydrogenase subunit 1; Drp1, dynamin-related protein 1; Mfn1, mitofusin 1; Mfn2, mitofusin 2.

protection against MIRI by improving mitochondrial function, including inhibiting the production of ROS and cytochrome $c$, increasing the opening of the MPTP, increasing the EC and regulating fission- and fusion-associated gene expression levels.

In addition to mitochondrial dysfunction, autophagy has been recently reported as a novel regulatory target during MIRI $(58,59)$; for example, one previous study observed that excessive autophagy during reperfusion triggered myocardial cell death (22). In the present study, it was found that MIRI dramatically induced autophagosome formation, as evidenced by transmission electron microscopy, which was consistent with a previous study (60). As the core kinase protein of the mTOR complex 1 (mTORC1), the activation of mTOR promotes the phosphorylation of its downstream effectors, including p70S6K and 4E-BP1, thus inducing cell growth and proliferation $(61,62)$. Moreover, mTOR represses unc-51-like autophagy activating kinase 1 (ULK1) through its phosphorylation on Ser757, which leads to the inhibition of autophagy (63). In addition, AMP-activated protein kinase (AMPK) is a crucial sensor for maintaining energy homeostasis (64), and it can also promote 
autophagy by directly activating ULK1 through phosphorylation on Ser317/777 under the conditions of glucose starvation (65). The current study suggested that HBO pretreatment may inhibit MIRI-induced autophagy through regulating the mTOR-mediated autophagy pathway, by increasing the expression levels of mTOR and 4E-BPland decreasing the expression levels of Atg5 and p53. Notably, numerous studies have demonstrated that crosstalk between autophagy and apoptosis exists $(66,67)$. Our previous study has demonstrated that the Bax family members, caspase cascade, and cardiomyocyte apoptosis were inhibited following HBO pretreatment (40). Thus, these results suggested that the cardioprotective mechanism of HBO may be involved in inhibiting mTOR-mediated autophagy.

Nonetheless, the present study has numerous limitations. It was observed that mitochondrial dysfunction and excessive autophagy occurred in the MIRI model following $30 \mathrm{~min}$ of ischemia and $1 \mathrm{~h}$ of reperfusion, as evidenced by transmission electron microscopy, immunohistochemistry and the analysis of mRNA expression levels. These findings have also been reported in numerous previous studies $(20,21,68,69)$. In the present study, HBO pretreatment was found to restore mitochondrial function and inhibit cardiomyocyte autophagy; therefore, it was hypothesized that the protective effect of HBO pretreatment may be related to the modulation of mitochondrial function and cell autophagy. However, the mechanism by which HBO pretreatment affects the cardiomyocyte mitochondria and autophagy remains to be further investigated. Secondly, several experimental methods were used to analyze the mitochondrial function, including EC, cytochrome $c$ levels, intracellular ROS production, the opening of the $\mathrm{MPTP}$, mitochondrial ultrastructure, mtDNA copy number and the mRNA expression levels of Drp 1, Mfn1 and Mfn2. In future experiments, experimental methods investigating the bioenergetics and the status of oxidative phosphorylation will be used to further determine the mitochondrial function.

In conclusion, the present study demonstrated that HBO pretreatment effectively protected rat hearts from MIRI. This effect may be related to the restoration of mitochondrial function and the inhibition of cardiomyocyte autophagy. Thus, these findings suggested that HBO treatment may be a useful agent for the mitigation of MIRI.

\section{Acknowledgements}

The authors would like to thank Dr Jianquan Li, from the Guangxi Medical University, China, for his technical support in immunohistochemistry.

\section{Funding}

This present study was supported by the National Natural Science Foundation of China (grant nos. 81701089 and 81960246), The Guangxi Natural Science Foundation (grant no. 2017GXNSFBA198010) and the Guangxi Sanitation Research Project (grant nos. Z2016582 and Z20201096).

\section{Availability of data and materials}

The datasets used and/or analyzed during the current study are available from the corresponding author on reasonable request

\section{Authors' contributions}

WC and LL wrote the manuscript. WC, LL, XC, XP, and $\mathrm{CC}$ performed the experiments. $\mathrm{ZN}$ collected the data and analyzed the data. CC designed the study, revised the manuscript and funded the research. All authors read and approved the final manuscript.

\section{Ethics approval and consent to participate}

All animal experimental procedures were approved by the Animal Ethical Committee of Guangxi Medical University.

\section{Patient consent for publication}

Not applicable.

\section{Competing interests}

The authors declare that they have no competing interests.

\section{References}

1. Nabel EG and Braunwald E: A tale of coronary artery disease and myocardial infarction. N Engl J Med 366: 54-63, 2012.

2. Writing Group Members, Mozaffarian D, Benjamin EJ, Go AS, Arnett DK, Blaha MJ, Cushman M, Das SR, Ferranti SD, Després JP, et al: Executive summary: Heart disease and stroke statistics-2016 update: A report from the American Heart Association. Circulation 133: 447-454, 2016.

3. Buja LM: Myocardial ischemia and reperfusion injury. Cardiovasc Pathol 14: 170-175, 2005.

4. Levisman J and Price MJ: Update on the guidelines for the management of ST-elevation myocardial infarction. Am J Cardiol 115 (Suppl 5): A3-A9, 2015.

5. Yellon DM and Hausenloy DJ: Myocardial reperfusion injury. N Engl J Med 357: 1121-1135, 2007.

6. Ibáñez B, Heusch G, Ovize M and Van de Werf F: Evolving therapies for myocardial ischemia/reperfusion injury. J Am Coll Cardiol 65: 1454-1471, 2015.

7. Lee MS: Role of mitochondrial function in cell death and body metabolism. Front Biosci (Landmark Ed) 21: 1233-1244, 2016.

8. Shen YQ, Guerra-Librero A, Fernandez-Gil BI, Florido J, García-López S, Martinez-Ruiz L, Mendivil-Perez M, Soto-Mercado V, Acuña-Castroviejo Dario, Ortega-Arellano H, et al: Combination of melatonin and rapamycin for head and neck cancer therapy: Suppression of AKT/mTOR pathway activation, and activation of mitophagy and apoptosis via mitochondrial function regulation. J Pineal Res 64: e12461, 2017.

9. Zhou H, Hu SY, Jin QH, Shi C, Zhang Y, Zhu PJ, Ma Q, Tian F and Chen YD: Mff-dependent mitochondrial fission contributes to the pathogenesis of cardiac microvasculature ischemia/reperfusion injury via induction of mROS-Mmediated cardiolipin oxidation and HK2/VDAC1 disassociation-involved mPTP opening. J Am Heart Assoc 6: e005328, 2017.

10. Shires SE and Gustafsson AB: Mitophagy and heart failure. J Mol Med (Berl) 93: 253-262, 2015.

11. Saito $T$ and Sadoshima J: Molecular mechanisms of mitochondrial autophagy/mitophagy in the heart. Circ Res 116: 1477-1490, 2015.

12. Scarffe LA, Stevens DA, Dawson VL and Dawson TM: Parkin and PINK1: Much more than mitophagy. Trends Neurosci 37: 315-324, 2014.

13. Hausenloy DJ and Scorrano L: Targeting cell death. Clin Pharmacol Ther 82: 370-373, 2007.

14. Liesa M, Palacin M and Zorzano A: Mitochondrial dynamics in mammalian health and disease. Physiol Rev 89: 799-845, 2009.

15. Ingerman E, Perkins EM, Marino M, Mears JA, McCaffery JM, Hinshaw JE and Nunnari J: Dnm1 forms spirals that are structurally tailored to fit mitochondria. J Cell Biol 170: 1021-1027, 2005 
16. Smirnova E, Griparic L, Shurland DL and van der Bliek AM: Dynamin-related protein Drp1 is required for mitochondrial division in mammalian cells. Mol Biol Cell 12: 2245-2256, 2001.

17. Rapaport D, Brunner M, Neupert W and Westermann B: Fzolp is a mitochondrial outer membrane protein essential for the biogenesis of functional mitochondria in Saccharomyces cerevisiae. J Biol Chem 273: 20150-20155, 1998.

18. Santel A and Fuller MT: Control of mitochondrial morphology by a human mitofusin. J Cell Sci 114: 867-874, 2001.

19. Hao M, Zhu S, Hu L, Zhu H, Wu X and Li Q: Myocardial ischemic postconditioning promotes autophagy against ischemia reperfusion injury via the activation of the nNOS/AMPK/mTOR pathway. Int J Mol Sci 18: 614, 2017.

20. Jian J, Xuan F, Qin F and Huang R: Bauhinia championii flavone inhibits apoptosis and autophagy via the PI3K/Akt pathway in myocardial ischemia/reperfusion injury in rats. Drug Des Devel Ther 9: 5933-5945, 2015.

21. Xuan F and Jian J: Epigallocatechin gallate exerts protective effects against myocardial ischemia/reperfusion injury through the PI3K/Akt pathway-mediated inhibition of apoptosis and the restoration of the autophagic flux. Int J Mol Med 38: 328-336, 2016.

22. Hariharan N, Zhai P and Sadoshima J: Oxidative stress stimulates autophagic flux during ischemia/reperfusion. Antioxid Redox Signal 14: 2179-2190, 2011.

23. Kang R, Zeh HJ, Lotze MT and Tang D: The Beclin 1 network regulates autophagy and apoptosis. Cell Death Differ 18: 571-580, 2011.

24. Yu L, McPhee CK, Zheng LX, Mardones GA, Rong YG, Peng JY, Mi N, Zhao Y, Liu ZH and Wan FY: Termination of autophagy and reformation of lysosomes regulated by mTOR. Nature 465 : 942-946, 2010

25. Han YF, Zhao YB, Li J, Li L, Li YG, Li SP and Li ZD Stat3-Atg5 signal axis inducing autophagy to alleviate hepatic ischemia-reperfusion injury. J Cell Biochem 119: 3440-3450, 2018.

26. Pópulo H, Lopes JM and Soares P: The mTOR signalling pathway in human cancer. Int J Mol Sci 13: 1886-1918, 2012

27. Bramham CR, Jensen KB and Proud CG: Tuning specific translation in cancer metastasis and synaptic memory: Control at the MNK-eIF4E axis. Trends Biochem Sci 41: 847-858, 2016

28. Foster SS, De S, Johnson LK, Petrini JH and Stracker TH: Cell cycle- and DNA repair pathway-specific effects of apoptosis on tumor suppression. Proc Natl Acad Sci USA 109: 9953-9958, 2012.

29. TasdemirE,MaiuriMC,GalluzziL,Vitale I,Djavaheri-Mergny M, D'Amelio M, Criollo A, Morselli E, Zhu C, Harper F, et al: Regulation of autophagy by cytoplasmic p53. Nat Cell Biol 10 676-687, 2008

30. Crighton D, Wilkinson S, O'Prey J, Syed N, Smith P, Harrison PR Gasco M, Garrone O, Crook T and Ryan KM: DRAM, a p53-induced modulator of autophagy, is critical for apoptosis Cell 126: 121-134, 2006.

31. Dekleva M, Neskovic A, Vlahovic A, Putnikovic B, Beleslin B and Ostojic M: Adjunctive effect of hyperbaric oxygen treatment after thrombolysis on left ventricular function in patients with acute myocardial infarction. Am Heart J 148: 031, 2004.

32. Bennett MH, Lehm JP and Jepson N: Hyperbaric oxygen therapy for acute coronary syndrome. Cochrane Database Syst Rev 7: CD004818, 2015.

33. Rusyniak DE, Kirk MA, May JD, Kao LW, Brizendine EJ, Welch JL, Cordell WH and Alonso RJ: Hyperbaric oxygen therapy in acute ischemic stroke: Results of the hyperbaric oxygen in acute ischemic stroke trial pilot study. Stroke 34 $571-574,2003$

34. Liu WC, Yang SN, Wu CW, Chen LW and Chan JY: Hyperbaric oxygen therapy alleviates carbon monoxide poisoning-induced delayed memory impairment by preserving brain-derived neurotrophic factor-dependent hippocampal neurogenesis. Crit Care Med 44: e25-39, 2016.

35. Fife CE, Eckert KA and Workman WT: Ethical issues, standards, and quality control in the practice of hyperbaric medicine. Springer, Switzerland. Textbook of Hyperbaric Medicine pp.597-608, 2016

36. Pan X, Chen C, Huang J, Wei H and Fan Q: Neuroprotective effect of combined therapy with hyperbaric oxygen and madopar on 6-hydroxydopamine-induced Parkinson's disease in rats. Neurosci Lett 600: 220-225, 2015.
37. Chen CX, Fan QP, Nong ZH, Chen W, Li YX, Huang LY, Feng DR, Pan XR and Lan SY: Hyperbaric oxygen attenuates withdrawal symptoms by regulating monoaminergic neurotransmitters and NO signaling pathway at nucleus accumbens in morphine-dependent rats. Neurochem Res 43: 531-539, 2018.

38. Chen CX, Huang LY, Nong ZH, Li YX, Chen W, Huang JP, Pan XR, Wu GW and Lin YZ: Hyperbaric oxygen prevents cognitive impairments in mice induced by $D$-galactose by improving cholinergic and anti-apoptotic functions. Neurochem Res 42: 1240-1253, 2017.

39. Chen X, Li Y, Chen W, Nong Z, Huang J and Chen C: Protective effect of hyperbaric oxygen on cognitive impairment induced by D-galactose in mice. Neurochem Res 41: 3032-3041, 2016.

40. Chen C, Chen W, Nong Z, Ma Y, Qiu S and Wu G: Cardioprotective effects of combined therapy with hyperbaric oxygen and diltiazem pretreatment on myocardial ischemia-reperfusion injury in rats. Cell Physiol Biochem 38: 2015-2029, 2016.

41. Bøtker HE, Hausenloy D, Andreadou I, Antonucci S, Boengler K, Davidson SM, Deshwal S, Devaux Y, Lisa FD, Sante MD, et al: Practical guidelines for rigor and reproducibility in preclinical and clinical studies on cardioprotection. Basic Res Cardiol 113: 018-0696, 2018.

42. Livak KJ and Schmittgen TD: Analysis of relative gene expression data using real-time quantitative PCR and the 2(-Delta Delta C(T)) method. Methods 25: 402-408, 2001.

43. Qiao X, Jia S, Ye J, Fang X, Zhang C, Cao Y, Xu C, Zhao L, Zhu Y, Wang L and Zheng M: PTPIP51 regulates mouse cardiac ischemia/reperfusion through mediating the mitochondria-SR junction. Sci Rep 7: 45379, 2017.

44. Cook SA, Sugden PH and Clerk A: Regulation of bcl-2 family proteins during development and in response to oxidative stress in cardiac myocytes: Association with changes in mitochondrial membrane potential. Circ Res 85: 940-949, 1999.

45. Farber JL: Mechanisms of cell injury by activated oxygen species. Environ Health Perspect 10 (Suppl 10): S17-S24, 1994.

46. Kalogeris T, Baines CP, Krenz M and Korthuis RJ: Cell biology of ischemia/reperfusion injury. Int Rev Cell Mol Biol 298: 229-317, 2012.

47. Zorov DB, Juhaszova M and Sollott SJ: Mitochondrial reactive oxygen species (ROS) and ROS-induced ROS release. Physiol Rev 94: 909-950, 2014.

48. Zhang T, Zhang Y, Cui MY, Jin L, Wang YM, Lv FX, Liu YL, Zheng W, Shang HB, Zhang J, et al: CaMKII is a RIP3 substrate mediating ischemia- and oxidative stress-induced myocardial necroptosis. Nat Med 22: 175-182, 2016.

49. Twig G, Elorza A, Molina AJA, Mohamed H, Wikstrom JD, Walzer G, Stiles L, Haigh SE, Katz S, Las G, et al: Fission and selective fusion govern mitochondrial segregation and elimination by autophagy. EMBO J 27: 433-446, 2008.

50. Brooks C, Wei Q, Cho SG and Dong Z: Regulation of mitochondrial dynamics in acute kidney injury in cell culture and rodent models. J Clin Invest 119: 1275-1285, 2009.

51. Estaquier J and Arnoult D: Inhibiting Drp1-mediated mitochondrial fission selectively prevents the release of cytochrome c during apoptosis. Cell Death Differ 14: 1086-1094, 2007.

52. Lander ES and Lodish H: Mitochondrial diseases: Gene mapping and gene therapy. Cell 61: 925-926, 1990.

53. Borst P and Grivell LA: The mitochondrial genome of yeast. Cell 15: 705-723, 1978.

54. Haendeler J, Dröse S, Büchner N, Jakob S, Altschmid J, Goy C, Spyridopoulos L, Zeiher AM, Brandt U and Dimmeler S: Mitochondrial telomerase reverse transcriptase binds to and protects mitochondrial DNA and function from damage. Arterioscler Thromb Vasc Biol 29: 929-935, 2009.

55. Ong SB, Subrayan S, Lim SY, Yellon DM, Davidson SM and Hausenloy DJ: Inhibiting mitochondrial fission protects the heart against ischemia/reperfusion injury. Circulation 121: 2012-2022, 2010.

56. Ong SB, Hall AR and Hausenloy DJ: Mitochondrial dynamics in cardiovascular health and disease. Antioxid Redox Signal 19: 400-414, 2013

57. Zhang Y, Zhang L, Zhang Y, Fan X, Yang WW, Yu BY, Kou JP and Li F: YiQiFuMai powder injection attenuates coronary artery ligation-induced heart failure through improving mitochondrial function via regulating ROS generation and CaMKII signaling pathways. Front Pharmacol 10: 381, 2019.

58. Ma H, Guo R, Yu L, Zhang Y and Ren J: Aldehyde dehydrogenase 2 (ALDH2) rescues myocardial ischaemia/reperfusion injury: Role of autophagy paradox and toxic aldehyde. Eur Heart J 32: 1025-1038, 2011 
59. Ma X, Liu H, Foyil SR, Godar RJ, Weinheimer CJ and Diwan A Autophagy is impaired in cardiac ischemia-reperfusion injury. Autophagy 8: 1394-1396, 2012.

60. Dong W, Yang R, Yang J, Ding J, Wu H and Zhang J: Resveratrol pretreatment protects rat hearts from ischemia/reperfusion injury partly via a NALP3 inflammasome pathway. Int J Clin Exp Pathol 8: 8731-8741, 2015.

61. Rabanal-Ruiz Y, Otten EG and Korolchuk VI: mTORC1 as the main gateway to autophagy. Essays Biochem 61: 565-584, 2017.

62. Yang $Z$ and Klionsky DJ: Mammalian autophagy: Core molecular machinery and signaling regulation. Curr Opin Cell Biol 22: 124-131, 2010.

63. Dan E, Joungmok K, Shaw RJ and Kun-Liang G: The autophagy initiating kinase ULK1 is regulated via opposing phosphorylation by AMPK and mTOR. Autophagy 7: 643-644, 2011.

64. Hardie DG: AMP-activated/SNF1 protein kinases: Conserved guardians of cellular energy. Nat Rev Mol Cell Biol 8: 774-785, 2007.

65. Kim J, Kundu M, Viollet B and Guan KL: AMPK and mTOR regulate autophagy through direct phosphorylation of Ulk1. Nat Cell Biol 13: 132-141, 2011.
66. Luo S and Rubinsztein DC: Apoptosis blocks Beclin 1-dependent autophagosome synthesis: An effect rescued by Bcl-xL. Cell Death Differ 17: 268-277, 2010.

67. Yang B and Zhao S: Polydatin regulates proliferation, apoptosis and autophagy in multiple myeloma cells through mTOR/p70s6k pathway. Onco Targets Ther 10: 935-944, 2017.

68. Liu CY, Zhang YH, Li RB, Zhou LY, An Tao, Zhang RC, Zhai M, Huang Y, Yan KW, Dong YH, et al: lncRNA CAIF inhibits autophagy and attenuates myocardial infarction by blocking p53-mediated myocardin transcription. Nat Commun 9: 29, 2018.

69. Guo X, Jiang H, Yang J, Chen J, Yang J, Ding JW, Li S, Wu H and Ding HS: Radioprotective $105 \mathrm{kDa}$ protein attenuates ischemia/reperfusion-induced myocardial apoptosis and autophagy by inhibiting the activation of the TLR4/NF- $\kappa \mathrm{B}$ signaling pathway in rats. Int J Mol Med 38: 885-893, 2016.

(c) (i) (9) This work is licensed under a Creative Commons Attribution-NonCommercial-NoDerivatives 4.0 International (CC BY-NC-ND 4.0) License. 